\title{
PRESCRIBING PATTERN OF NSAIDS USED IN ORTHOPEDIC OUT PATIENT DEPARTMENT IN TWO TERTIARY HOSPITALS IN MYMENSINGH
}

\author{
SHAHNAZ $\mathrm{T}^{1}$, RAHMAN KA ${ }^{2}$, KAMAL AHMM ${ }^{3}, \mathrm{NAHAR} \mathrm{H}^{4}$, SHAHNAWAZ SS ${ }^{5}$, ISLAM MJ ${ }^{6}$, \\ RAHMAN MA ${ }^{7}$
}

\begin{abstract}
Context: Non-steroidal anti-inflammatory drugs (NSAIDs) are most commonly used drugs for years for management of pain and inflammation with good efficacy. NSAIDs are increasingly used for variety of indications like rheumatoid arthritis (RA), osteoarthritis (OA), low back pain (LBP) etc. Prescribing patterns need to be evaluated periodically to increase the therapeutic efficacy, decrease adverse effects and provide feedback to prescribers. A prospective observational study was conducted among patients attending the Out Patient Department (OPD) of Orthopedic and received prescription for NSAIDs in the Mymensingh Medical College Hospital (MMCH) and Community Based Medical College Hospital (CBMCH) in Mymensingh.

Material and Methods: The study was carried out on 300 (three hundreds) prescriptions for NSAIDs from orthopedic Out Patient Department (OPD) of Mymensingh Medical College Hospital (MMCH) and Community Based Medical College Hospital (CBMCH). A prospective observational study was conducted from January 2015 to December 2015. Data were collected only from the patients prescribed for NSAIDs and prescribing pattern of NSAIDs were analyzed using SPSS method version 20.1

Results: In case of orthopedic OPD patients most common NSAIDs prescribed to the patients was aceclofenac (29.33\%). Others NSAIDs prescribed to the patient in pain management were ketorolac (10\%), etoricoxib(8\%), ibuprofen (9\%), naproxen(9\%), sulindac (7\%) in orthopedic out patients of both Medical College Hospitals. Most of the NSAIDs were prescribed in brand name (85.34\%) where only (14.76\%) were prescribed in generic name in both hospitals.

Conclusion: From the study it was observed that aceclofenac was the most common NSAIDS used in orthopedic OPD of CBMCH and indomethacin was the most common used NSAIDs in $M M C H$. Other used NSAIDs were ketorolac, naproxen, etoricoxib, ibuprofen and sulindac.
\end{abstract}

Key words: Prescribing Pattern, NSAID drug, Orthopedic Department.

J Dhaka Med Coll. 2018; 27(2) : 195-198

\section{Introduction:}

According to International Association for the Study of Pain, it is 'an unpleasant sensory and emotional experience associated with actual or potential tissue damage, or described in terms of such damage'. Furthermore 'Pain is always subjective. Each individual learns the application of the word through experiences related to injury in early life" ${ }^{\text {. A }}$ A wide range of disease conditions involve pain and fever as symptoms. From the very beginning of human civilization, man has been trying to find the way of controlling these symptoms and maintaining good health. As a result, non-steroidal antiinflammatory drugs (NSAIDs) prescribing as an adjunct to therapy is widely practiced. The lowering of pain thus is an important part of the perception of cure and the overall well-being of the patient ${ }^{1}$. Non-steroidal anti-inflammatory drugs (NSAIDs) are most commonly used drugs

1. Dr. Tasmin Shahnaz, Assistant Professor, Department of Pharmacology. Ibn Sina Medical College, Dhaka.

2. Dr. Kazi Afzalur Rahman, Associate Professor, Department of Pharmacology, Dhaka Medical College, Dhaka.

3. Dr. A.H.M Mostafa Kamal, Associate Professor, Department of Anatomy, Dhaka Medical College, Dhaka.

4. Dr. Habibun Nahar, Assistant Professor, Department of Pharmacology, Marks Medical College, Dhaka.

5. Dr. Sabrina Shammi Shahnewaz, Assistant Professor, Department of Pharmacology, East West Medical College, Dhaka.

6. Dr. Md. Jubaidul Islam, Registrar, Department of Medicine, BIRDEM General Hospital, Dhaka

7. Dr. Mohammad Abdur Rahman, Junior Consultant Medicine, Jinjira 20 bedded Hospital, Kerajiganj

Correspondence : Dr. Tasmin Shahnaz, Assistant Professor, Department of Pharmacology , Ibn Sina Medical College Dhaka, Cell Phone: 01932005694,E-mail: shahnaztasmin@gmail.com.

Received: 12 May 2018

Revision: 26 August 2018

Accepted: 08 September 2018

https://doi.org/ 10.3329/jdmc.v27i2.45833 
for years for management of pain and inflammation with good efficacy and represent most widely prescribed class of medications in the world and are used as over the counter drugs. They work by interfering with cyclooxygenase (COX) pathway, which involves the conversion of arachidonic acid by the enzyme COX to prostaglandins. COX is available in two isoforms i.e. COX-1 and COX-2 $2^{2}$. The COX-1 enzyme is constitutive and control physiological functions such as stomach mucus production and kidney water excretion as well as platelet formation. In contrast COX-2, is involved in producing prostaglandins for inflammatory response. The intention is to recognize whether current patterns of prescribing, dispensing and use of drug therapy are reliable with criteria and standards. These criteria and standards demonstrate the drug therapy is effective, safe, appropriate, and cost effective and support optimal patient outcome. The ultimate goal of this drug utilization research is to evaluate the prescribing pattern of NSAIDs in both medical college hospitals. In spite of considerable improvements in the availability and control of drugs in hospitals, rational drug use is still a worldwide problem ${ }^{3}$..

The aim of this study is to obtain information regarding the prescribing pattern of NSAIDs by the medical prescribers in the outpatient departments of two selected medical college hospitals in Mymensingh district. The outpatient departments have been chosen because both rural and urban population of different classes and socio-economic background daily come to these outpatient departments from various parts of Mymensingh district to take treatment of their common diseases. The prescribing pattern of NSAIDs in the outpatient departments of sub-urban level hospitals are often copied by community practitioners and health workers. Needless to say that these unqualified community practitioners and health workers tremendously influence the drug utilization pattern in the community and often contribute to misuse and over utilization of drugs. ${ }^{4}$ Keeping present scenario in mind, a prospective study was planned and conducted in the Department of Pharmacology and in Orthopaedics OPD of a Mymensingh Medical College Hospital and Community Based Medical College Hospital from January-2015 to December-2015 to analyze the prescribing pattern of NSAIDs.

\section{Materials and Methods:}

The present study was performed on 300 (Three hundred) prescriptions of both sexes from orthopedic Out Patient Department (OPD) of Mymensingh Medical College Hospital $(\mathrm{MMCH})$ and Community Based Medical College hospital (CBMCH) in Mymensingh as tertiary level hospital in Bangladesh. Among them 150 (One hundred and fifty) prescriptions were included from patients attended in orthopedic OPD of MMCH and 150 (One hundred and fifty ) prescriptions from patients attended in orthopedic OPD of $\mathrm{CBMCH}$ in Mymensingh. The check list type of data was collected with prior permission from the concern department and the authority. The study was cross sectional descriptive type and was conducted in the department of Pharmacology, Mymensingh Medical College from January 2015 to December 2015. Data were collected and analyzed by SPSS 20.1.

\section{Ethical Clearance:}

The study was approved by the Ethical Review Committee of Mymensingh Medical College, Mymensingh.

\section{Result:}

Table-I shows the distribution of NSAIDs prescribed to the patient in pain, management in orthopedic OPD of Mymensingh Medical College Hospital and Community Based Medical College Hospital. In case of orthopedic OPD patients most common NSAIDs was indomethacin(29.33\%) (Figure-1). Others NSAIDs were ketorolac (10.33\%), ibuprofen (8.67\%), naproxen (9\%), etoricoxib $(7.67 \%)$ and sulindac(6.67\%). Table-II shows the distribution of NSAIDS used in Mymensingh Medical College Hospital and Community based Medical College Hospital. Indomethacin was used $29.33 \%$ and $27.33 \%$ in $\mathrm{MMCH}$ and $\mathrm{CBMCH}$ respectively. Aceclofenac was used $21.33 \%$ and $37.33 \%$ in $\mathrm{MMCH}$ and $\mathrm{CBMCH}$ respectively. Sulindac was used in $12 \%$ and $1.33 \%$, naproxen was used in $14 \%$ and $4 \%$ ibuprofen was used in $12 \%$ and $5.33 \%$, ketorolac was used in $10 \%$ and $10.66 \%$ in Mymensingh Medical College Hospital and Community Based Medical College Hospital respectively. Etoricoxib was used in $3.33 \%$ orthopedic OPD patients in $\mathrm{CBMCH}$ and $12 \%$ in $\mathrm{MMCH}$ (Figure-2). 
Table-I

Distribution of NSAIDS prescribed in Out Patient Department of the two medical colleges $(n=300)$

\begin{tabular}{lcc}
\hline NSAIDs & $\begin{array}{c}\text { Frequency } \\
(\mathrm{n}=300)\end{array}$ & $\begin{array}{c}\text { Percentage } \\
(\%)\end{array}$ \\
\hline Aceclofenac & 88 & $29.33 \%$ \\
Indomethacin & 85 & $28.33 \%$ \\
Sulindac & 20 & $6.67 \%$ \\
Naproxen & 27 & $9 \%$ \\
Ibuprofen & 26 & $8.67 \%$ \\
Ketorolac & 31 & $10.33 \%$ \\
Etoricoxib & 23 & $7.67 \%$ \\
\hline Total & 300 & $100 \%$ \\
\hline
\end{tabular}

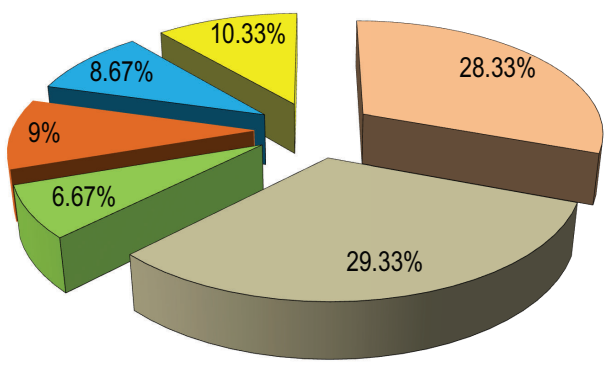

口Indomethacin $\square$ Aceclofenac $\square$ Sulindac -Naproxen ulbuprofen $\square$ Ketorolac

Fig.-1: NSAIDS prescribed in Out Patient Department of the two medical colleges $(n=300)$.

\section{Table-II}

Distribution of NSAIDs Used in Mymensingh Medical College Hospital (MMCH) and Community Based Medical College Hospital (CBMCH)

\begin{tabular}{lcc}
\hline Distribution of NSAIDS & \\
Name of NSAIDs & $\mathrm{MMCH}$ & $\mathrm{CBMCH}$ \\
& $\mathrm{n}=150(\%)$ & $\mathrm{n}=150(\%)$ \\
\hline Indomethacin & $44(29.33 \%)$ & $41(27.33 \%)$ \\
Aceclofenac & $32(21.37 \%)$ & $56(37.33 \%)$ \\
Sulindac & $2(1.33 \%)$ & $18(12 \%)$ \\
Naproxen & $21(14 \%)$ & $6(4 \%)$ \\
Ibuprofen & $18(12 \%)$ & $8(5.33 \%)$ \\
Ketorolac & $15(10 \%)$ & $16(10.66 \%)$ \\
Etoricoxib & $18(12 \%)$ & $5(3.33 \%)$ \\
\hline \multicolumn{3}{c}{ Total $150(100 \%)$} \\
\hline \multicolumn{3}{c}{$150(100 \%)$} \\
\hline
\end{tabular}

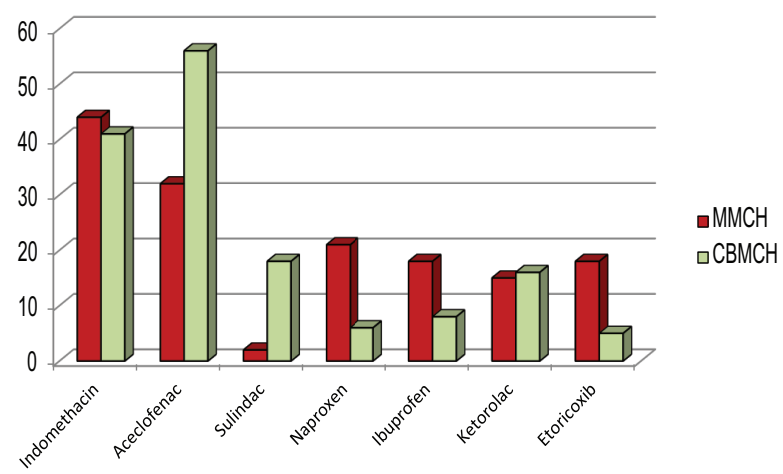

Fig.-2: Bar diagram showing the comparison of number of using NSAIDs in orthopedic OPD of $M M C H$ and $C B M C H$.

\section{Discussion:}

The study was performed on 300 (three hundreds) prescriptions of both sexes from orthopedic outpatient department of Mymensingh Medical College Hospital and Community Based Medical College Hospital. Among them 150 (one hundred and fifty) prescription were included from patients attended in outpatient department of Mymensingh Medical College Hospital and 150 (one hundred and fifty) prescriptions were included from patients attended Community Based Medical College Hospital, Mymensingh. Most common NSAIDs prescribed to the orthopedic OPD patients in both Hospital were aceclofenac $(29.33 \%)$, indomethacin $(28.33 \%)$, ketorolac $(10.33 \%)$, naproxen $(9 \%)$, etoricoxib (7.67\%), sulindac (6.67\%), ibuprofen $(8.67 \%)$ (Table-I, Figure-1). A study was done by Mahadi ${ }^{5}$ and others where found indomethacin $(2.8 \%)$ and $(2 \%)$ patients in general and specialized hospitals which is a little bit different to our study. A study was done on Pune Maharastra ${ }^{6}$ where aceclofenac was prescribed in (30\%). In our study aceclofenac (37.33\%) was the most common prescribing NSAIDs in orthopedic OPD of Community Based Medical College. This study is quiet similar to our study. One study was done by Sharma et $\mathrm{al}^{7}$ found that ibuprofen was prescribed $(7 \%)$ and in our study Ibuprofen was prescribed (8.67\%) which is quiet similar to our study. Another study in Korea $^{8}$, where ibuprofen was absent in prescription which is totally reverse from this study. A study was done on Pokhra ${ }^{9}$, where 
naproxen was prescribed (9\%) which is quiet similar to our study. In the present study, ketorolac was prescribed to (10.33\%). A study was done on Mahadietal. ${ }^{5}$ where ketorolac was prescribed to (29\%), which is different from our study. Etoricoxib was a COX-2 selective NSAIDS, in present study etoricoxib was prescribed $(7.67 \%)$. A study was done in Rahman et $\mathrm{al}^{1}$ where etoricoxib was prescribed $(8 \%)$ patients at $\mathrm{DMCH}$ and $(12 \%)$ at private Hospital which is quiet similar to this study. In our study, sulindac was prescribed (6.67\%) where, a study was done by Lee ${ }^{10}$ and others, where no one was prescribed sulindac in Korea which is quiet reverse from our study.

\section{Conclusion:}

Non-steroidal anti-inflammatory drugs are most commonly used drug for the management of pain and inflammation. From our study it was observed that seven types of NSAIDS are used in both Mymensingh Medical College Hospital and Community Based Medical College Hospital. NSAIDs are vital for clinical management but it is mostly accompanied by gastrointestinal complication. For healing of NSAIDs-associated ulcers or ulcer complication we used effective well-tolerated adjuvant drugs such as PPI and $\mathrm{H}_{2}$ receptor antagonist. Indomethacin $(29.33 \%)$ was the main drug used in $\mathrm{MMCH}$ and aceclofenac (37.33\%) was the main drug used in $\mathrm{CBMCH}$. Other NSAIDs were ketorolac, naproxen, ibuprofen, etoricoxib, sulindac. NSAIDs was used in generally brand name $(85.34 \%)$ with a few generic name.

Conflict of interest: Not declared by authors

\section{References:}

1. Rahman, M., Begum, Z. and Samad, M. Prescribing Pattern of Non-Steroidal Anti-Inflammatory Drugs at Outpatient Departments of Teaching Hospitals. Bangladesh J Pharmacol 2008;2(1): 9-13.
2. Vane, J. Inhibition of Prostaglandin Synthesis as a Mechanism of Action for Aspirin-like Drugs. Nat New Biol 1971;231(25):232-35.

3. Mohammed, T.C.H., Beegum, I.M. \& Perumal, P. Prescribing pattern of analgesics in a tertiary care hospital. International Journal of PharmTech Research 2011;3(3): 1521-29.

4. Foegh, M. L., M. Hecker, P. W. Ramwell. The eicosanoids: Prostaglandins, Thromboxanes, Leukotrienes and Related Compounds. Seventh Edition ed. In Basic and Clinical Pharmacology, ed. B. G. Katzung, Stamford, Connecticut, USA: Appleton \& Lange;1998:304-18.

5. Mahadi, H.M. et al. Study on the Use Pattern of Nsaids in Some General and Specialized Hospitals of Bangladesh. International Research Journal of Pharmacy 2012;3(2):152-55.

6. Medical Multimedia Group. Spine University's Guide to Low Back Pain and NSAIDs. [online] Medical Multimedia Group. Available at: https:// www.google.com.bd/ search?q=Spine+University\% $\mathrm{E} 2 \% 80 \% 99 \mathrm{~s}+\mathrm{Guide}+\mathrm{to}+\mathrm{Low}+\mathrm{Back}+\mathrm{Pain}+\mathrm{and}+$ NSAIDs \&oq=Spine+University\%E2\%80\%99s + Guide+to+Low+Back+Pain+and+NSAIDs\&aqs= chrome..69i57. 188963j0j4\& sourceid=chrome\&es_ $\mathrm{sm}=93 \& \mathrm{ie}=\mathrm{UTF}-8 \#$ (Accessed 1 Jan. 2015).

7. Sharma, T., Dutta, S. and Dhasmana, D. Prescribing Pattern of NSAIDS in Orthopaedic OPD of a Tertiary Care Teaching Hospital in Uttaranchal. Journal of Medical Education \& Research 2006;8(3): 42-4.

8. Lee, S., Han, C., Yang, I. and Ha, C. Prescription Pattern of NSAIDs and the Prevalence of NSAIDinduced Gastrointestinal Risk Factors of Orthopaedic Patients in Clinical Practice in Korea. Journal of Korean Medical Science 2011;26(4):561.

9. Shankar, P.R. et al. Prescribing Patterns in the Orthopaedics Outpatient Department in A Teaching Hospital in Pokhara, Western Nepal. Kathmandu University Medical Journal 2007;5(17):16-21.

10. Lee, S., E. Soyoola, P. Chanmugam, S. Hart, W. Sun, H. Zhong, S. Liou, D. Simmons, D. Hwang. Selective Expression of Mitogen-Inducible Cyclooxygenase in Macrophages Stimulated with Lipopolysaccharide. J BiolChem 1992;267: 25934-25938. 